\title{
COMMISSION 46: TEACHING OF ASTRONOMY (ENSEIGNEMENT DE L'ASTRONOMIE)
}

President: E. A. Müller.

\author{
Report of Meetings
}

SECRETARY: D. G. Wentzel.

Session 1, 22 August 1973

Fifteen Commission members or their representatives were present. The Commission Report was approved; the National Reports were extended by J.-C. Pecker who reported the introduction of astronomy as a regular part of the physics teaching in French schools from age 13 on.

The nomination of D. McNally as Commission President, the appointment of two additional Commission members (S. K. Trehan, India, and Th. Schmidt, German Federal Republic) and of two consulting members (B. Hajebi, Iran, and R. H. Wilkinson, Australia) were approved. The discussion on whether the Commission should propose to the IAU Executive Committee two vicepresidents or one involved (i) the difficulties of successful actions when correspondence is involved with a single vice-president in a country that is not used to rapid postal communications, '(ii) the difficulty of the vice-president representing the president at a meeting when the vice-president cannot leave his country readily, and (iii) the difficulties inherent in choosing specific duties and establishing the succession to the presidency in case of two vice-presidents. The majority of voting members favored proposing two vice-presidents to the Executive Committee.

The Commission members took note of a meeting between Australian Science Teachers and astronomers, organized through Commission 46 on August 20, 1973, which proved stimulating to all participants. Discussion centered on how the resolution that emerged from the meeting with the teachers could be made effective in Australia and at the same time would encourage teaching efforts in other countries. The following two resolutions were passed with no dissenting votes:

Resolution 1: "Considering the effort made by Australian teachers to improve the teaching of Astronomy, the IAU Commission No. 46 on Teaching of Astronomy earnestly recommends to the XVth General Assembly of the IAU that the Australian National Committee on Astronomy be requested to seek funds from the Australian Government to further the teaching of Astronomy in Australian Primary and Secondary Schools, through continuing the development of Curriculum Materials in Astronomy and the extension of in-service training in Astronomy for Australian Teachers.'

Resolution 2: 'The IAU Commission 46 (Teaching of Astronomy) earnestly recommends that the appropriate authorities in the various adhering countries be requested to actively support the efforts of teachers endeavouring to introduce curricular developments in astronomy.'

The Commission then discussed the financial support needed (i) to organize one International School for Young Astronomers per year, and (ii) to develop the project of the Visiting Professors. The following motion requesting financial support from the IAU Executive Committee was passed:

Recommendation: 'In order to support some of its educational projects Commission No. 46 requests from the IAU the following financial aid (in order of priority):

1. For the International Schools for Young Astronomers and/or for Astronomy Courses for Science Teachers in developing countries the sum of $\$ 20000$. - over three years.

2. For the Visiting Lecturers' Project the sum of $\$ 6000$. - over three years.'

Both these projects of the Commission are organized for the benefit of astronomers in remote institutions and in developing countries. Discussion of the motion suggested that item 2 should 
emphasize the educational benefits that might accrue to the country visited by a visiting lecturer, at whatever level of teaching this might be accomplished best.

Teleki presented the following proposals submitted to the IAU by Yugoslavia:

(1) 'The IAU, valueing the advancement of astronomical knowledge of young people, asks the Executive Committee and Commission 46 to investigate the possibility of organizing young astronomers' competitions, in different regions of the world, under the patronage and the organisation of the Union.'

The level of the proposed competitions would include secondary schools. Successful astronomy competitions exist already in Poland and Yugoslavia. President Müller and others stressed the difficulty of regional competitions given the great diversity of astronomy teaching in adjacent countries, and the relative large funding required to organize and run such competitions. It was pointed out that science fairs (which include all sciences) are already organized in many countries. The Commission came to the conclusion that this proposal was not feasible. Instead, the Commission proposed the following recommendation:

'Commission 46 recommends to its national delegates that they (or their national adhering organisations) support local and national competitions by making available information on how successful competitions are run, by helping science fairs find astronomers to judge astronomical entries, etc.'

(2) The second proposal by Yugoslavia refered to 'the establishment of a centre for exchange and loan of temporarily unused astronomical instruments and accessories.'

President Müller pointed out that a Working Group on Exchange of Equipment was formed at the XIVth General Assembly in Brighton (1970) consisting of representatives of Commissions 9 and 46. The chairman of the Working Group is N. N. Mikhelson, G. Abell and D. McNally were the Commission 46 representatives. D. McNally reported that in early 1972 the Working Group sent out a circular letter to ascertain those observatories which had equipment out of regular use that could be loaned to other observatories (preferably those of developing countries). No positive feedback was received to this circular. President Müller stressed the great difficulties involved in providing for packing and customs and other formalities if such equipment actually became available. The Commission came to the conclusion that also the second proposal by Teleki was not feasible. Instead, 'the Commission recommends that institutions which may have surplus equipment, which they are willing to donate or give on loan, prepare such lists and send these to the IAU Secretariat for publication in the IAU Information Bulletin. It should be stressed, however, that the receiving institutions must be in charge of all the custom, packing and shipping formalities.'

\section{Sessions 2 and 3, 25 August 1973}

The rules and guidelines proposed for the Commission were approved, subject to minor corrections suggested by Commission members. Copies of these rules and guidelines will be mailed to all Commission members.

President Müller summarized the various forms of cooperation that she has persued with the ICSU Committee on Science Teaching, with the UNESCO Division of Science Teaching, and with COSTED (Committee on Science and Technology in Developing Countries). She briefly reported on the ICSU/UNESCO Conference on "Education of Teachers for Integrated Science" held at the University of Maryland (USA) from 3 to 13 April 1973. The emphasis of this Conference was the education of teachers (both initial and in-service) to teach science in both integrated and coordinated ways. The Proceedings of the Conference will be published by UNESCO in the New Trend series. Among the future plans of the ICSU Committee on Science Teaching is a meeting of the full Committee dealing with the integration, separation or coordination of science teaching at university level. A subsequent discussion on the integration of astronomy into other science courses or curricula showed mainly that the needs and opportunities in the various countries differ tremendously. Those without astronomy courses look toward integration, those with courses do not. Yet in some countries more astronomy can be taught when integrated with physics than as a separate 
subject; this is the case for example in Bulgarian schools, as reported in a letter by N.S. Nikolov.

The collaboration with UNESCO concerns mainly the organization of both the schools for young astronomers and the elementary astronomy courses for school science teachers in developing countries. In future years, the elementary astronomy courses (such as the Kenya courses of August 1972) might be sponsored by UNESCO's Division of Pre-University Science and Technology. For the international schools for young astronomers financial support might be sought through UNESCO's Division of Scientific Research and Higher Education. President Müller stressed, however, that institutions interested in having Commission 46 organize either a school for young astronomers or elementary astronomy courses for school science teachers should make the first steps themselves by contacting both the Commission President and the UNESCO Field Service in their own country.

In a letter R. J. Chambers, who taught the 1972 elementary astronomy courses for Kenya science teachers, pointed out the lack of texts and materials keyed to various geographical regions, in particular to equatorial regions. He stressed the following remarks:

'The importance of observer-centered phenomena cannot be overemphasized. Aspects of the sky, rotation and revolution of the earth, weather and timekeeping, navigation, solar energy, and uses of artificial satellites for communications, meteorology, and geological surveys are vitally important to people in developing countries. A very large proportion of these people live in equatorial latitudes. If they are to participate in the application of this technology, and of the benefits which astronomy and space science potentially can bring to them, they must have adequate grounding in the fundamental concepts involved. To people in developing nations, the most relevant portion of the science for their lives is what generally comes under the heading of 'practical astronomy', to which might be added 'classical space science'. Yet these topics are the ones that are most susceptible to variation in presentation, depending on the geographical locale of the intended students.' Further on R. J. Chambers stressed that 'simple texts in astronomy are needed, including teachers' editions with lesson plans for all grade levels. Materials for secondary schools should have highest priority, because it is from this level that talented students are identified and selected for higher studies. Teacher's editions will serve to bridge the gap at teachers' colleges until college level materials can be prepared. The needs for primary schools are less important only in terms of scheduling. Most of the people in developing countries still attend only primary school. They won't be taught until their teachers are prepared, however, hence the suggested sequence of secondary, college, and finally primary level publications. Finally, the existence of television facilities in most countries opens the possibility of pre-packaged courses on astronomy which can short-cut the time necessary to train teachers.'

The training of astronomers in developing countries was treated by B. Hidayat (Indonesia) who emphasized that arrangements between small and advanced institutions should pay attention to the capability of the student upon return to his own institution, and that such exchanges need to be augmented by regional cooperation and through extended visits by professors so that they could profitably interact with the local students. S. Ferraz Mello pointed out that 'the main task for training scientists in developing countries is to provide a high-level scientific manpower; the two specific tasks concerning astronomers are (i) to form the appropriate scientists for the already existing and for the planned institutes for astronomical research, and (ii) to train the teaching staff for the universities in which astronomy is being taught at undergraduate and graduate level.' He then summarized how Brazil built up a core of astronomers starting in 1961 (i) by sending young people abroad for graduate training, (ii) by having visiting professors teaching in Brazil, and (iii) by starting graduate courses (since 1967) when the first graduated Brazilians returned from abroad. He emphasized that the young people sent abroad for graduate training in astronomy must have had a good training in physics and mathematics at their home institution. Furthermore it is important that the institutes hosting young people from developing countries integrate them in the research staff and not only have them follow some graduate courses. In addition S. Ferraz Mello stressed the need for Visiting Professors (both for shorter and longer stays) in developing countries. 
Concerning the Young Astronomers' Schools President Müller expressed the deep appreciation of the Commission to the Secretary of the schools, J. Kleczek, and to the directors of the schools, Z. Kopal (Manchester), M. Rigutti (Arcetri), R. V. Karandikar (Hyderabad), J. Sahade (Cordoba), B. Hidajat (Lembang), - for their great efforts in organizing and running the schools. Our last School for Young Astronomers was held from July 23 to August 18, 1973, at the Bosscha Observatory in Java (Indonesia). The participants came from Indonesia (5), India (1), Japan (1), and South Africa (1). D. G. Wentzel was the principal lecturer who stayed for the entire duration of the school. The collaboration of five other foreign lecturers could be secured for up to one week each, due to the fact that they were on their way to the IAU General Assembly in Sydney. In a letter J. Kleczek mentioned that 'the fundamental aspect of all our schools was the enthusiastic endeavour of all the lecturers and assistants, and this was the impressive feature which made the schools so successful and useful for many young astronomers from many different countries.' If financial support is available, the schools for Young Astronomers are to be continued. It should be stressed that they consist not only of lecture courses but include practical and observing work and discussions, so as to maximize the benefits to the individual students who tend to come from very diverse backgrounds.

Various regional schools and advanced courses were mentioned, such as the Saas-Fee courses of the Swiss Society of Astronomy and Astrophysics. They are considered to be important and very useful, and they should be given more publicity. It was suggested that they should be announced in the IAU Information Bulletin.

D. McNally pointed out the increasing need to ensure that postgraduate students realize the structure of scientific life (organization, financial support, etc.).

The rest of the session was devoted to a discussion on teaching aids in Astronomy. The list of Astronomy Educational Material and its 1973 Addendum proved to be extremely useful. A second Addendum will be prepared for 1976 and should emphasize quality material. A careful selection of the available materia] must be made by each individual national representative after consultation with his colleagues, students and interested astronomy teachers in his own country. The members of the Organizing Committee in charge of preparing the 1976 Addendum are as follows: T. L. Swihart for part A (English), E. V. Kononovich for part B (Slavic languages), and H. E. Jørgensen for part $C$ (other languages).

C. Zwaan summarized the series of Dutch television lessons in Astronomy. It was also mentioned that Astronomy lessons on television may become available through the British Open University.

Refering to the Contratype Project, President Müller congratulated Miss M. Gerbaldi, E. V Kononovich, and D. G. Wentzel for the amount of work they have put into this project, and the French astronomers in particular are to be congratulated for the donations which they have made in this direction. It was, however, pointed out that in order to make the photographs directly useful, they must be accompanied by a detailed description of what they represent and what they are used for. In view of the difficulty of having materials returned if any general dissemination were begun, it was decided to reproduce the materials where they are, but only for individuals actively engaged in curriculum development and who would make the materials more generally useful. Later various centers may be established for wider distribution.

Further discussions concerned laboratory exercises, the self-paced Astronomy studies such as reported by L. Houziaux, and the better dissemination of astronomy educational opportunities via regional journals and journals of teachers' associations.

As for the Book Project it was suggested that, similar to the exchange of instructional equipment, announcements of available materials for donation or for loan should be made through the $I A U$ Information Bulletin. The possible influence of UNESCO or IAU at customs of various countries was discussed.

\section{Session 4, 28 August 1973}

Reported by D. McNally.

A series of educational films were shown illustrating the types available for popular audiences, 
for higher school and for early university audiences. A single example of a research film was also screened. The choice of films reflected the effort put into the production of educational films in the Western Hemisphere and the ease of access. The suggestions of various Commission members were acknowledged, though not all of them could be adopted. The Commission is most grateful to the commercial firms who made the films freely available. The films shown were the following: Exploring the Milky Way; The Birth and Death of a Star; A New Look at the Sun; The Solar Atmosphere; Fields of Space; Storms on the Sun; The Star System; Ursae Majoris; The Motion of Stars; Algol; Force, Mass and Motion; Hubble's Variable Nebula. Details concerning these films may be obtained by writing to $D$. McNally.

\section{Special Session with Australian Science Teachers, 20 August 1973}

Chatrman: D. McNally.

SECRETARY: M. B. Wilkinson.

The day preceding the opening of the XVth General Assembly of the IAU in Sydney, Commission 46 had a full day session together with Australian science teachers of primary and secondary school level. This meeting was arranged because Commission 46 considered it to be important that the Commission members should make contact with teachers and those concerned with curricular development in schools.

Approximately 70 teachers from N.S.W., 3 from Queensland and 1 from Victoria were present.

The papers read at the meeting were as follows:

D. McNally: Astronomy and the Physical Sciences.

D. G. Wentzel: Astronomy in Higher Education.

A. K. Carey: The Context of Australian Science Education.

R. H. Wilkinson: Astronomy in Australian Education.

J. Alexander: Astronomy in Elementary Education.

T. H. Dickson: Astronomy in Secondary Education in N.S.W.

The meeting permitted a valuable contact between the teachers and professional astronomers. Exchange of ideas on teaching aids and materials took place which was of value to the teachers. Of value to the astronomers was the reminder that they should be aware (i) of their actions in promoting the teaching of astronomy, and (ii) of the conceptional limitations of the children.

An interesting part of the programme was the reading of some reports of projects by children in the age group 8 to 10 . These reports clearly demonstrated some of the conceptual problems involved at this level. Again the attention of the Commission was brought to the excellent astronomical teaching aids provided by the Junior School Science Project.

However, the greatest single point that was brought out was the need for in-service courses on astronomy for interested teachers. Most teachers meet astronomy when responding to the interests of the pupils and it was felt that teachers could be more responsive if they were aware of fundamental astronomical knowledge. It is important that Commission 46 itself should consider in the future the problems posed in providing such in-service training courses. While recognizing that such courses can be instituted in some countries, assistance to others through the project for teacher training and the visiting professor project should be actively pursued.

Finally, a resolution was framed, discussed and approved concerning the development of curriculum materials in Astronomy and the extension of in-service training in Astronomy for Australian science teachers. This resolution was discussed and passed in the first session of the Commission on August 22.

A more detailed account of the Proceedings of the meeting with Australian science teachers will be distributed to all Commission members and it is hoped that it will be published in the Journal of the Australian Science Teachers Association. 